\title{
Comparison of the effect of Ips and pam3 on ventilated lungs
}

\author{
Hans P Hauber*1,2, Dörte Karp'1, Torsten Goldmann³, Ekkehard Vollmer ${ }^{3}$ and Peter Zabel²
}

\begin{abstract}
Background: While lipopolysaccharide (LPS) from Gram-negative bacteria has been shown to augment inflammation in ventilated lungs information on the effect of Gram-positive bacteria is lacking. Therefore the effect of LPS and a lipopetide from Gram-positive bacteria, PAM3, on ventilated lungs were investigated.

Methods: C57/Bl6 mice were mechanically ventilated. Sterile saline (sham) and different concentrations of LPS (1 $\mu \mathrm{g}$ and $5 \mu \mathrm{g}$ ) and PAM3 (50 nM and $200 \mathrm{nM}$ ) were applied intratracheally. Lung function parameters and expression of MIP-2 and TNFa as well as influx of neutrophils were measured.

Results: Mechanical ventilation increased resistance and decreased compliance over time. PAM3 but not LPS significantly increased resistance compared to sham challenge $(P<0.05)$. Both LPS and PAM3 significantly increased MIP-2 and TNFa mRNA expression compared to sham challenge $(P<0.05)$. The numbers of neutrophils were significantly increased after LPS at a concentration of $5 \mu \mathrm{g}$ compared to sham $(P<0.05)$. PAM3 significantly increased the numbers of neutrophils at both concentrations compared to sham $(P<0.05)$.

Conclusions: These data suggest that PAM3 similar to LPS enhances ventilator-induced inflammation. Moreover, PAM3 but not LPS increases pulmonary resistance in ventilated lungs. Further studies are warranted to define the role of lipopetides in ventilator-associated lung injury.
\end{abstract}

\section{Background}

Invasive mechanical ventilation is a life saving approach in severe respiratory failure. However, large tidal, high inspiratory pressures, and end-exspiratory alveolar collapse with cyclic reopening can damage the lung parenchyma leading to ventilator-induced lung injury (VILI) [1-6]. Several studies have provided insight into the pathogenesis of VILI and the underlying inflammatory processes (reviewed in [7]).

One major problem in mechanically ventilated patients is ventilator-associated pneumonia (VAP). Incidence rates in the intensive care unit (ICU) vary from $8 \%$ to $28 \%$ [8]. Mortality rates can reach $76 \%$ depending on high-risk pathogens [8]. A number of potential causative factors have been identified (e. g. orotracheal tube, impaired mucociliary clearance, severely ill patients, multiresistant bacteria) [9]. In addition, previous studies have demonstrated that bacterial products such as lipopolysaccharide (LPS) from Gram-negative bacteria augment ventilator-

\footnotetext{
* Correspondence: hphauber@fz-borstel.de

1 Pathophysiology of Inflammation, Research Center Borstel, Borstel, Germany Full list of author information is available at the end of the article
}

induced inflammation [10-12]. Most of that previous work has focussed on expression of inflammatory mediators and inflammatory cells. Changes in lung function parameters have been less well characterized. Moreover, LPS has been administered systemically or intratracheally before the beginning of ventilation [10-12].

In contrast to LPS, data on the effect of Gram-positive bacteria on inflammation and lung function in ventilated lungs are lacking despite the importance of Gram-positive bacteria in VAP [8]. Therefore we sought to compare the functional and structural effects of intratracheal application of Gram-negative and Gram-positive bacterial products to ventilated lungs in a mouse model of mechanical ventilation. We chose to compare the effect of LPS to a lipopetide form the outer cell membrane of bacteria, PAM3.

\section{Methods}

Animal preparation

Experiments were carried out in accordance with the Animal Protection Law of Germany. All experiments were approved by the local Ethics Committee. 10- to 12- 
week old male C57/Bl6 mice (Charles River Labs, Berlin, Germany) (25-35 g) were anesthetized by intraperitoneal injection of ketamine $(100 \mathrm{mg} / \mathrm{kg})$ and xylazin $(20 \mathrm{mg} /$ $\mathrm{kg})$. Additional anesthetic was given when animals start to gain consciousness as assessed by positive testing of paw reflex. Body temperature was maintained with a homeothermic blanket system with flexible probe (Harvard Apparatus, Holliston, USA). After tracheostomy with a secured 18-gauge metal cannula mechanical ventilation was initiated using a flexivent (Scireq, Montreal, Canada) computer-controlled small animal ventilator. Oxygen saturation and pulse rate were monitored using the MouseOx oximeter (Starr Life Science, Pittburgh, PA). The sensor was placed on the back leg along the leg axis. The mice were covered throughout the experiments to maintain body temperature.

\section{Protocols}

After anesthesia mice were randomized to different groups. All mice were mechanically ventilated with a tidal volume ( $\mathrm{Vt}$ ) of $10 \mathrm{ml} / \mathrm{kg}$ and a positive end-expiratory pressure (PEEP) of $2 \mathrm{~cm} \mathrm{H2O}$. Breath rate was 120/min. Inspiratory fraction of oxygen was 0.21 (normal air). 9 mice were only ventilated without any challenge (control group). Intratracheal application was performed $30 \mathrm{~min}$ after start of ventilation with the nebulizer system form flexivent (Ana-B1/8, Scireq, Montreal, Canada) because after $30 \mathrm{~min}$ a plateau was reached for resistance. The total volume of solution was $50 \mu \mathrm{L}$ (in $10 \mathrm{sec}$ ) in every condition. Challenges included sterile saline (sham, $\mathrm{N}=$ 5), $1 \mu \mathrm{g}$ LPS $(\mathrm{N}=6), 5 \mu \mathrm{g}$ LPS $(\mathrm{N}=8), 50 \mathrm{nM}$ PAM3 $(\mathrm{N}=$ 5), and $200 \mathrm{nM}$ PAM3 $(\mathrm{N}=6)$. After $120 \mathrm{~min}$ of ventilation animals were sacrificed. At the end of each experiment the lung of each animal was divided into two parts. One part was immediately snap frozen in liquid nitrogen for later RNA extraction. The other part was put into formalin for later histological examination.

\section{Lung function measurements}

At the beginning, every $15 \mathrm{~min}$ and at the end of mechanical ventilation a TLC (total lung capacity) manoeuvre was performed. With this manoeuvre lungs are inflated with a pressure of up to $30 \mathrm{~cm} \mathrm{H}_{2} \mathrm{O}$ for a total of six seconds in order to standardize the volume history and to prevent pre-existing atelectasis. During mechanical ventilation lung function measurements were performed every $5 \mathrm{~min}$ using the flexivent ventilator. Resistance and compliance were determined with forced manoeuvres (volume of approximately $200 \mu \mathrm{l}$ ) on the basis of a single compartment model of the lungs as described previously [13]. Newtonian resistance, tissue damping and elastance were obtained using the forced oscillation technique that fits the constant-phase model to input impedence [13]. Briefly, this perturbation involves an 8-s signal, which uti- lizes a range of frequencies, including $0.5,0.75,1.25,1.75$, $2.75,3.25,4.25,4.75,5.75,7.25,9.25,10.25,11.75,14.75$, $16.75,18.25$, and $19.75 \mathrm{~Hz}$.

\section{Histological measurements}

Prior to fixation lungs were inflated until total lung capacity. Formalin fixed tissue specimens were sectioned and stained with hematoxilin eosin (HE) according to standard protocols. Numbers of polymorphonuclear leukocytes (PMN) were counted per high powered field $\left(0.25 \mathrm{~mm}^{2}\right)$ by two independent observers in a blinded fashion. The within observer coefficient of variation was less than $5 \%$.

\section{RNA extraction and reverse transcription}

RNA from whole lung tissue samples was extracted using an RNeasy Mini Kit (Qiagen). Reverse transcription was performed with 0.5-1.0 $\mu \mathrm{g}$ of RNA per reaction using Superscript II reverse transcriptase (RT, 200 U per reaction) (Invitrogen) and oligo-dT in the presence of an RNase inhibitor (RNase Out, Invitrogen). The RNA was reverse transcribed in $30 \mu \mathrm{l}$ of total volume at $65^{\circ} \mathrm{C}$ for 10 $\mathrm{min}$, at $42^{\circ} \mathrm{C}$ for $60 \mathrm{~min}$, and at $100^{\circ} \mathrm{C}$ for $1 \mathrm{~min}$. The resultant first-strand complementary DNA (cDNA) was used as template for PCR.

\section{Quantitative real time PCR (QRTPCR)}

QRTPCR was carried out using a LightCycler system (Roche Diagnostics, Mannheim, Germany). Macrophage inflammatory protein (MIP)-2 mRNA, tumour necrosis factor (TNF) $\alpha$ mRNA and hypoxanthine phosphoribosyltransferase (HPRT) mRNA expression was quantified using QRTPCR. MIP-2 and TNF $\alpha$ were selected as proinflammatory cytokines with well known up-regulation in VILI and after LPS challenge. HPRT was used as house keeping gene. Primers were based on published mRNA sequences and were designed to span at least two exons in order to avoid binding to genomic DNA. Specific amplification using these primers was confirmed by ethidium bromide staining of the predicted size of the PCR products on an agarose gel. PCR was performed using the QuantiTect SYBR Green PCR Kit (Qiagen) with the appropriate primers and samples according to the manufacturer's protocol. In brief, $1 \mu \mathrm{l}$ of cDNA was added to $10 \mu \mathrm{l}$ of $2 \times$ QuantiTect SYBR Green PCR master mix, $8 \mu \mathrm{l}$ of RNase-free water, and $0.5 \mu \mathrm{l}$ of each primer $(20 \mu \mathrm{M})$ resulting in a total volume of $20 \mu \mathrm{l}$. All PCR experiments were carried out in triplicate.

\section{Statistics}

Changes in lung function parameters were assessed by comparison of the values at the time of challenge ( $30 \mathrm{~min}$ after the beginning of ventilation) and the values at the end of the experiment (120 min). For comparison of values at the beginning and at the end of the experiment in 
one group a paired $t$ test was used. For comparison between different groups an overall ANOVA on ranks, followed by multiple testing with the Bonferroni correction, was performed. Differences between groups were assessed by means of post hoc pairwise comparison with the Dunnet test (Systat version 7.0, SPSS Inc, USA). A P value of less than 0.05 was considered statistically significant. All values are given as means \pm SD if not otherwise stated.

\section{Results}

\section{Effect of LPS and PAM3 on lung function parameters}

Resistance increased during mechanical ventilation in all groups (Figure 1A). The strongest increase was observed with PAM3. PAM3 at concentrations of $50 \mathrm{nM}$ and 200 nM significantly increased total resistance ( $R$; 2.1 -fold and 1.9-fold, respectively) and tissue damping (G; 1.7-fold and 2.3-fold) from the time of challenge to the end of the experiment $(\mathrm{P}<0.05)$ (Figure $2 \mathrm{~A})$. No significant effect was observed with Newtonian resistance $(\mathrm{Rn})$ (Figure 2A). Sham challenge and LPS challenge had no significant effects on these parameters $(\mathrm{P}>0.05)$ (Figure 1A and 2A).

Stimulation with PAM3 also significantly increased elastance (1.9-fold and 2.4-fold, respectively) $(\mathrm{P}<0.05)$. No significant effect was noted in the other groups $(\mathrm{P}>$ 0.05) (Figure 2B). Compliance decreased during mechanical ventilation in all groups (Figure 1B). PAM3 led to a significant decrease $(60 \%$ and $40 \%$, respectively) ( $\mathrm{P}<$ 0.05 ) whereas no significant reduction was observed in the other groups (Figure $2 \mathrm{C}$ ).
Effect of LPS and PAM3 on oxygen saturation and heart rate There was no statistically significant difference in oxygen saturation and heart rate between the control group, the sham group and the challenge groups (data not shown) ( $\mathrm{P}$ $>0.05)$

\section{Effect of LPS and PAM3 on pro-inflammatory cytokine expression}

Mechanical ventilation alone significantly increased MIP2 and TNF $\alpha$ mRNA expression in the lungs compared to spontaneously breathing controls (33.3-fold and 5.7-fold, respectively; $\mathrm{P}<0.05)$. Intratracheal challenge with $\mathrm{NaCl}$ (sham) further increased cytokine expression. This effect was significant for TNFa (4.4-fold; P < 0.05) but not for MIP-2 (1.7-fold; P > 0.05) compared to ventilation alone. LPS significantly increased MIP-2 (5.5-fold and 7.9-fold, respectively; $\mathrm{P}<0.05)$ and TNF $\alpha$ mRNA expression (15.1-fold and 36.3-fold, respectively; $\mathrm{P}<0.05$ ) in a dose dependent manner compared to sham challenge. PAM3 also significantly increased MIP-2 (3.3-fold and 3.2-fold, respectively; $\mathrm{P}<0.05)$ and TNF $\alpha$ mRNA expression (9.4fold and 11.8-fold, respectively; $\mathrm{P}<0.05)$ compared to sham challenge. No dose dependency was observed with PAM3. LPS had a stronger effect on cytokine expression compared to PAM3 reaching statistical significance at a dose of $5 \mathrm{ng} / \mathrm{mL}(\mathrm{P}<0.05)$ (Figure $3 \mathrm{~A}$ and $3 \mathrm{~B})$.

\section{Effect of LPS and PAM3 on neutrophil inflammation in ventilated lungs}

Ventilation alone as well as sham challenge had no significant effect on the numbers of neutrophils in the lungs

\section{A}

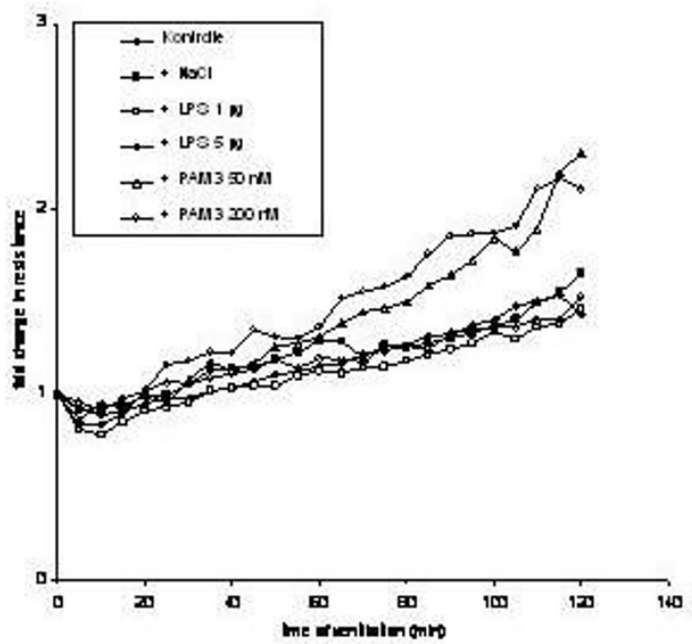

B

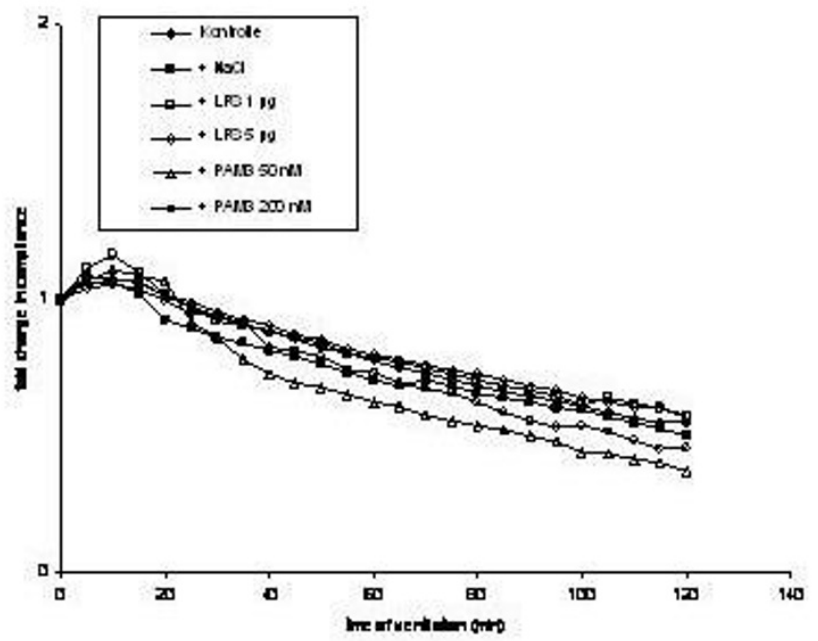

Figure 1 Relative changes in resistance (A) and compliance (B) during mechanical ventilation alone and after challenge with sterile saline (sham), LPS (1 $\mu \mathrm{g}$ and $5 \mathrm{\mu g}$ ) and PAM3 (50 $\mathrm{nM}$ and $200 \mathrm{nM}$ ). Mean values are shown. 


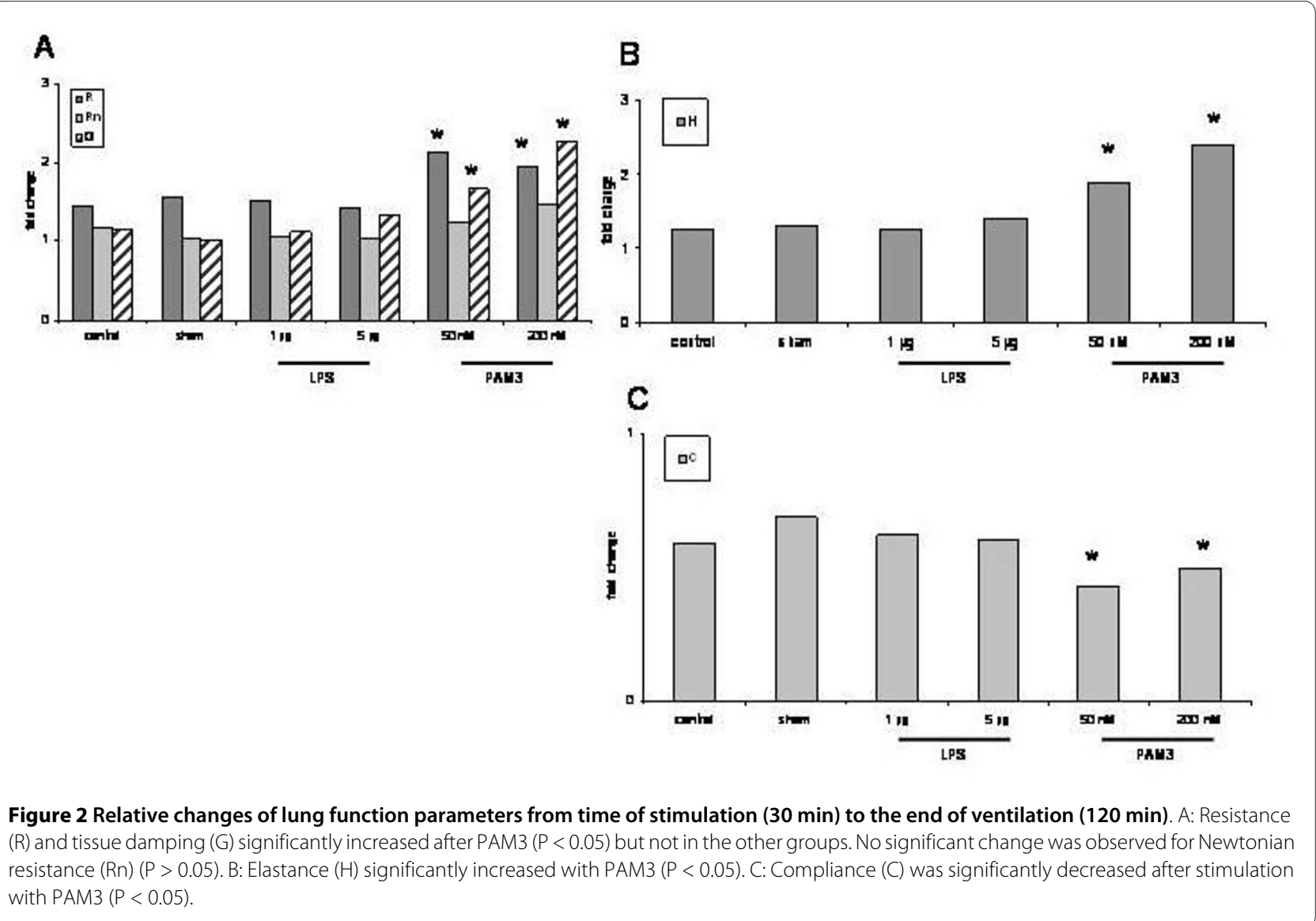

compared to spontaneously breathing animals $(23.0 \pm$ 2.1 /field and $18.6 \pm 2.2$ /field vs $20.0 \pm 2.5$ /field $)(P>0.05)$. LPS increased neutrophil numbers in a dose dependent manner. This effect was significant at a dose of $5 \mu \mathrm{g}(35.0$ \pm 4.0 /field $)$ compared to sham $(\mathrm{P}<0.05)$. PAM3 also significantly increased numbers of neutrophils being significant at both tested concentrations (34.0 $\pm 1.5 /$ field and $38.3 \pm 2.6 /$ field $)(\mathrm{P}<0.05)$ (Figure 4 and 5$)$.

\section{Discussion}

In the present study we investigated the effects of inhalation of Gram-negative and Gram-positive bacterial products on mechanically ventilated lungs. We found that both LPS and PAM3 augmented lung inflammation. Moreover, PAM3 but not LPS led to a significant increase in pulmonary resistance.

Previous studies have demonstrated inflammation due to mechanical ventilation $[7,14]$. In those studies mostly high tidal volume ventilation was compared to low tidal ventilation (protective ventilation) $[15,16]$. Several reports have demonstrated that LPS can further increase VILI or can augment inflammation in lungs receiving a protective ventilation strategy. However, in those studies LPS was applied before beginning of ventilation or systemically [10-12]. Data on the effect of LPS application on already ventilated lungs are sparse. Therefore we challenged ventilated animals with LPS. Agreeing with previous data we found increased inflammation when LPS was added to ventilated lungs.

PAM3 is a lipopetide from bacteria that binds to TLR-2 [17]. Although up-regulation of TLR-2 by mechanical ventilation has been reported previously data on the effect of PAM3 on ventilated lungs are sparse [18]. In the present study PAM3 enhanced ventilator-associated inflammation similar to LPS. However, the effect of LPS on pro-inflammatory cytokine expression and neutrophil influx was stronger compared to PAM3. We did not measure protein levels of cytokines in bronchoalveolar lavage fluid but previous studies have shown increased cytokine protein levels after LPS challenge [10]. It is not very likely that there may be difference between mRNA and protein expression after PAM3 challenge. However, this has to be considered as a limitation of our study.

We did not challenge unventilated mice with LPS or PAM3. Therefore we can only compare the effect of LPS and PAM3 in ventilated mice. However, both LPS and PAM3 further enhanced inflammation in ventilated lungs compared to sham challenge.

In the present study we show for the first time that a TLR-2 agonist, PAM3, is able to augment ventilator-asso- 


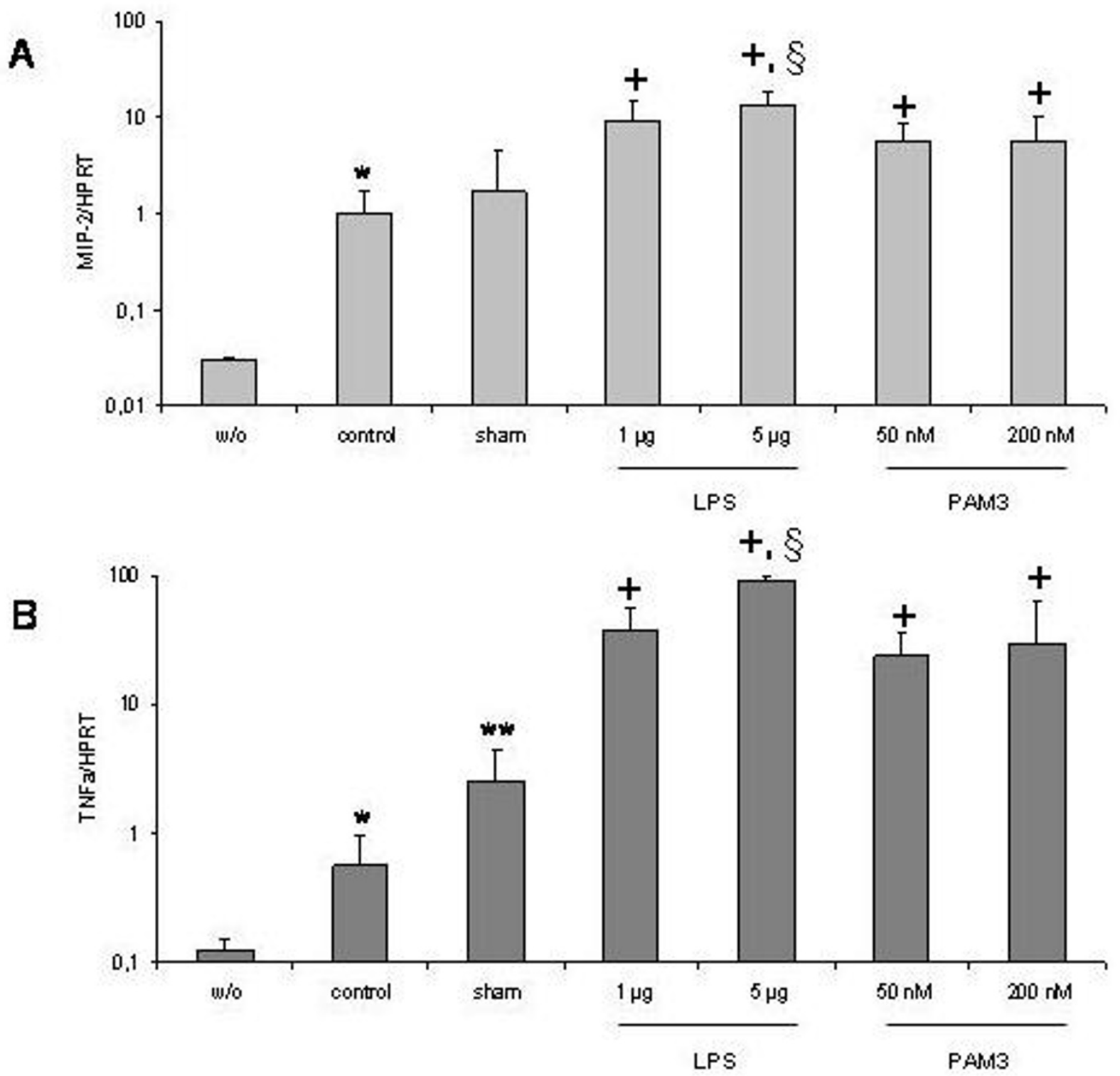

Figure 3 MIP-2 (A) and TNFa (B) gene expression in the mouse lung of spontaneously breathing animals (w/o, without mechanical ventilation) and mechanical ventilated animals without challenge (control), with intratracheal saline challenge (sham) and with challenge with LPS or PAM3 at different doses. Bars indicate mean+SEM. *: $P<0.05$ vs spontaneously breathing mice. ${ }^{* *}: \mathrm{P}<0.05$ vs control. + : $P<0.05$ vs sham. $\S$ $P<0.05$ vs PAM3 challenge.

ciated inflammation. Recent data from the literature have questioned the role of TLR-2 in ventilator-induced inflammation [18]. Our results do not necessarily support a role for TLR-2 in the pathogenesis of VILI but they show that TLR-2 activation may be important in enhancing ventilator-induced inflammation. This finding is supported by clinical practice since VAP caused by Grampositive bacteria can be observed frequently [10]. However, our study was not designed to investigate susceptibility to infection in ventilated lungs. The role of TLR-2 in this setting remains to be further evaluated.
Interestingly in our study PAM3 challenge led to a significant increase in resistance compared to LPS and sham challenge. LPS has been shown to induce pulmonary and vascular hyperreactivity in mice [19]. In that study LPS had no effect on resistance. LPS has also been demonstrated to induce bronchial hyperresponsiveness in humans [20]. We found no increase in pulmonary resistance after LPS. This agrees with data from previous reports. In contrast the functional effects of TLR-2 agonists have not been characterized very well. To our knowledge this is the first study to investigate the effect of 


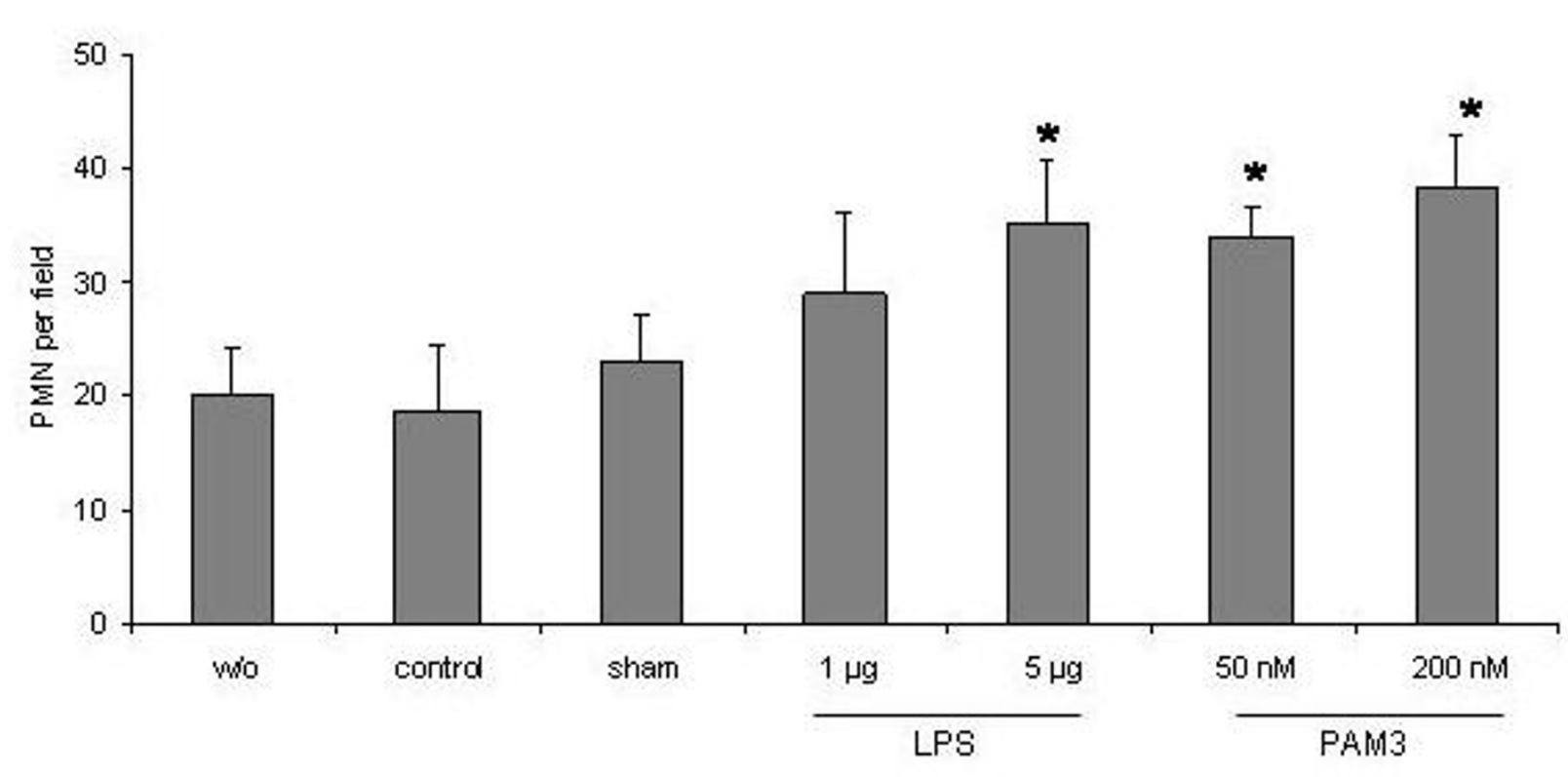

Figure 4 Numbers of polymorphonuclear cells (PMN) per high powered field in the mouse lung of spontaneously breathing animals (w/o, without mechanical ventilation) and mechanical ventilated animals without challenge (control), with intratracheal saline challenge (sham) and with challenge with LPS or PAM3 at different doses. Bars indicate mean+SEM. *: $P<0.05$ vs sham.

intratracheal PAM3 application on lung function parameters. At present it remains unclear how PAM3 augments pulmonary resistance. However, using more sophisticated analysis we found that PAM3 increased total resistance and tissue damping which represents tissue resistance. In contrast, no effect was observed in resistance of the central airways (Newtonian resistance). This finding suggests that PAM3 has an effect in the lung parenchyma and in the small airways but not in the cen-

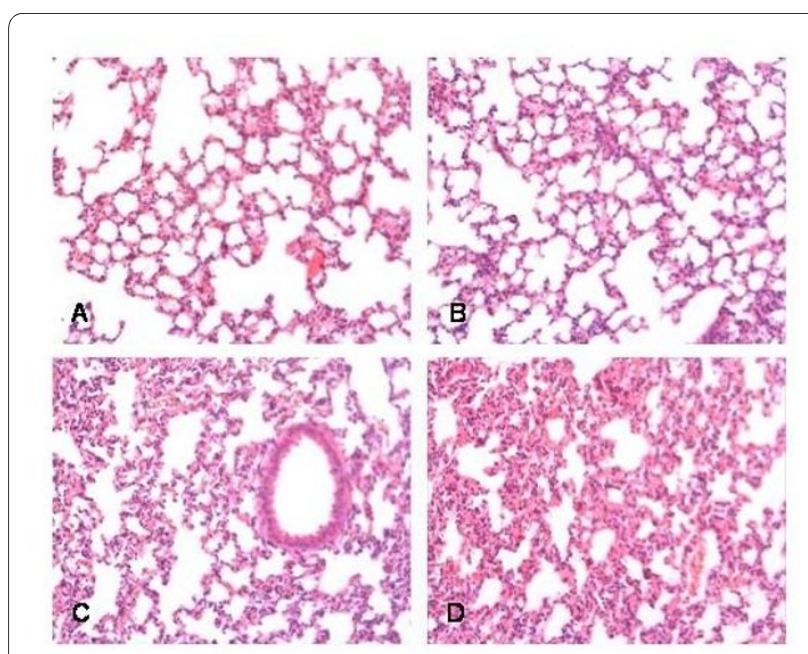

Figure 5 Histology sections of mouse lungs with ventilation alone (A), after sham challenge (B), after LPS challenge $(5 \mu \mathrm{g})(\mathrm{C})$, and after PAM3 challenge (200 nM) (D). HE staining. Original magnification $\times 100$. tral airways. In addition, only PAM3 challenge significantly decreased compliance and led to a significant increase in elastance.

\section{Conclusion}

In conclusion in our study we found that both LPS and PAM3 can further increase ventilator-induced inflammation. In contrast to LPS PAM3 significantly increased resistance. The underlying mechanisms are under current investigation. It is tempting to speculate that bacterial infection of ventilated lungs amplifies VILI and that increased resistance due to PAM3 in case of Gram-positive bacterial infection may support bacterial colonization and airway obstruction. Future studies will have to further evaluate the effect of PAM3 on ventilated lungs and ventilator-associated inflammation.

\section{Competing interests}

The authors declare that they have no competing interests.

\section{Authors' contributions}

$\mathrm{HPH}$ and PZ designed the experimental protocol, did the data analysis and wrote the manuscript. HPH and DK performed the experiments. TG und EV did the pathologic analysis. All authors read and approved the final manuscript.

\section{Author Details}

1Pathophysiology of Inflammation, Research Center Borstel, Borstel, Germany, ${ }^{2}$ Medical Clinic, Research Center Borstel, Borstel, Germany and ${ }^{3}$ Experimental Pathology, Research Center Borstel, Borstel, Germany

Received: 21 July 2009 Accepted: 20 April 2010

Published: 20 April 2010 


\section{References}

1. Parker JC, Hernandez LA, Peevy KJ: Mechanisms of ventilator-induced lung injury. Crit Care Med 1993, 21:131-143.

2. Corbridge TC, Wood LD, Crawford GP, Chudoba MJ, Yanos J, Sznajder J: Adverse effects of large tidal volume and low PEEP in canine acid aspiration. Am Rev Respir Dis 1990, 142:311-315.

3. Dreyfuss D, Soler P, Basset G, Saumon G: High inflation pressure pulmonary edema: respective effects of high airway pressure, high tidal volume, and positive end-expiratory pressure. Am Rev Respir Dis 1988, 137:1159-1164.

4. Peevy KJ, Hernandez LA, Moise AA, Parker JC: Barotrauma and microvascular injury in lungs of nonadult rabbits: effect of ventilation pattern. Crit Care Med 1990, 18:634-637.

5. Tsuno K, Prato P, Kolobow T: Acute lung injury from mechanical ventilation at moderately high airway pressures. J App/ Physiol 1990, 69:956-961.

6. Muscedere JG, Mullen JBM, Gan K, Slutsky AS: Tidal ventilation at low pressures can augment lung injury. Am J Respir Crit Care Med 1994, 149:1327-1334.

7. Frank JA, Matthay MA: Science review: Mechanisms of ventilatorinduced injury. Critical Care 2003, 7:233-241.

8. Chastre J, Fagon JY: Ventilator-associated pneumonia. Am J Respir Crit Care Med 2002, 165:867-903

9. Torres A, Carlet J: Ventilator-associated pneumonia. European Task Force on ventilator-associated pneumonia. Eur Respir J 2001 17:1034-1045.

10. Altemeier WA, Matute-Bello G, Gharib SA, Glenny RW, Martin TR, Liles WC: Modulation of lipopolysaccharide-induced gene transcription and promotion of lung injury by mechanical ventilation. J Immuno/ 2005, 175:3369-3376

11. Altemeier WA, Matute-Bello G, Frevert CW, Kawata Y, Kajikawa O, Martin TR, Glenny RW: Mechanical ventilation with moderate tidal volumes synergistically increases lung cytokine response to systemic endotoxin. Am J Physiol Lung Cell Mol Physiol 2004, 287:L533-L542.

12. Gharib SA, Liles WC, Matute-Bello G, Glenny RW, Martin TR, Altemeier WA: Computational identification of key biological modules and transcriptional factors in acute lung injury. Am J Respir Crit Care Med 2006, 173:653-658.

13. Bates $\mathrm{JH}$ : Understanding lung tissue mechanics in terms of mathematical models. Monaldi Arch Chest Dis 1993, 73:134-139.

14. Ranieri VM, Suter PM, Trotorella C, De Tullio R, Dayer JM, Birenza A, Bruno F, Slutsky AS: Effect of mechanical ventilation on inflammatory mediators in patients with acute respiratory distress syndrome: a randomized controlled trial. JAMA 1999, 282:54-61.

15. Imanaka H, Shimaoka M, Matsuura N, Nishimura M, Ohta N, Kiyono H: Ventilator-induced lung injury is associated with neutrophil inflammation, macrophage activation, and TGF-beta1 upregulation in rat lungs. Anesth Analg 2001, 92:428-436.

16. Tremblay L, Valenza F, Ribeiro SP, Li J, Slutsky AS: Injurious ventilation strategies increase cytokines and c-fos mRNA expression in an isolated rat lung model. J Clin Invest 1997, 99:944-952.

17. Takeda K, Takeuchi H, Akira S: Recognition of lipopeptides by Toll-like receptors. J Endotoxin Res 2002, 8:459-463.

18. Vaneker M, Joosten LA, Heunks LM, Snijdelaar DG, Halbertsma FJ, van Egmond J, Netea MG, Hoeven JG van der, Scheffer GJ: Low-tidal-volume mechanical ventilation induces a toll-like receptor 4-dependent inflammatory response in healthy mice. Anesthesiology 2008, 109:465-472.

19. Held HD, Uhlig S: Mechanisms of endotoxin-induced airway and pulmonary hyperreactivity in mice. Am J Respir Crit Care Med 2000 162:1547-1552.

20. Michel O, Duchateau J, Sergysels R: Effect of inhaled endotoxin on bronchial reactivity in asthmatic and normal subjects. J Appl Physio 1989, 66:1059-1064.

Pre-publication history

The pre-publication history for this paper can be accessed here: http://www.biomedcentral.com/1471-2466/10/20/prepub

doi: $10.1186 / 1471-2466-10-20$

Cite this article as: Hauber et al., Comparison of the effect of Ips and pam3 on ventilated lungs BMC Pulmonary Medicine 2010, 10:20

\section{Submit your next manuscript to BioMed Central} and take full advantage of:

- Convenient online submission

- Thorough peer review

- No space constraints or color figure charges

- Immediate publication on acceptance

- Inclusion in PubMed, CAS, Scopus and Google Scholar

- Research which is freely available for redistribution

Submit your manuscript at www.biomedcentral.com/submit
C) Biomed Central 